\title{
NOVEL EXCIPIENTS AS DIFFERENT POLYMERS: A REVIEW
}

\author{
Deepak Heer* and Gaurav Swami
}

\author{
Rayat and Bahra Institute of Pharmacy, Sahauran, Kharar, District Mohali, Punjab, India-140104
}

*Corresponding Author's Email: heerkangra@gmail.com, Contact no: 098729-49211

\begin{abstract}
Novel excipient is a new chemical entity, a new innovation that has not been used in any drug approved by regulatory authorities. Market trends suggest that pharma companies are not eager to use novel excipients because they don't want to add additional risks to product being developed as regulatory authority might not approve drug product because of new excipient. Apart from this, pharma companies are also worried about reliable supply from GMP production facilities while using novel excipients. The USFDA also encourages innovation in excipients to develop new drugs or improve approved therapeutics and IPEC is helping to drive acceptance of these novel products into the market. The objective of the present research is to assess the use of different polymers as novel excipients in the development of suitable pharmaceutical dosage forms. These novel excipients used as surface active agents, keratolyticagents,bioreagentsandThe identified excipients were also studied for their physical and chemical properties along with their regulatory requirements.
\end{abstract}

Keywords:Novelexcipient,denimers, co-polymers,Surface active agent,keratolytic agent.

\section{INTRODUCTION}

Over the past decades, excipient suppliers have developed novel mixtures and new physical forms of excipients that are tailored to the needs of newer delivery platforms (transdermal, pulmonary, oral modified release). Most excipient manufacturers however concentrate on modifying existing excipients as opposed to developing entirely new ones. This is so because regulatory restrictions have made innovation rather difficult. Under US law, an excipient cannot be sold for use in approved drugs unless it can be qualified through one or more of the three FDA approval mechanisms. These include determination by FDA that the substance is "generally recognized as safe" (GRAS), is approved through a food additive petition, or is referenced in an approved new drug application (NDA) for a particular function in that specific drug product.

The International Pharmaceutical Excipients Council (IPEC) spells out 13 general categories of excipients for solid dosage forms based on function: binders, disintegrants, fillers, lubricants, glidants, compression aids, colors, sweeteners, preservatives, suspending /dispersing agents, film formers/coatings, flavors, and printing inks. This Update paper cites a few examples, where novel excipients or existing excipients in novel roles caused a significant improvement in product performance.

\section{EXCIPIENT SYNERGIES MULTIFUNCTIONALITY:}

AND

\section{Improving Flowability}

Today, it is not unheard of to have tableting equipment compressing 8,000 to 10,000 tablets per minute. It is critical under these conditions to have an excellent flowing granulation/powder blend. Many sugar-based excipients, such as maltose, mannitol, and sorbitol are not compressible in their natural state and need to be modified for use in direct compression tableting.

Advantose $^{\mathrm{TM}} 100$ maltose powder (SPI Polyols) is a disaccharide carbohydrate, with flow and tableting (c) 2011, JDDT. All Rights Reserved properties that are greatly improved by the process of spray drying. Spray-dried Advantose $\mathrm{T}^{\mathrm{TM}} 100$ particles are spherical with an optimal combination of fine and coarse particles that contributes to superior flow. When compared to microcrystalline cellulose (MCC), spray-dried maltose can tolerate significantly greater compression forces (>4000 lb) without capping

upon ejection from the tableting die. It also exhibits lower hygroscopicity and lower reactivity; thus providing more stable tablets as compared to those made with MCC.

\section{Formulating a High-Dose Active Formulation}

Formulations prepared using a high concentration of active or multiple actives pose challenges, such as segregation of powder blends, low content uniformity, and poor flow. Such formulations require excessive amounts of conventional binders, such as MCC and dicalcium phosphate (DCP) to achieve workable compactibility. Maintaining tablet size then becomes an additional cause of concern.

ProSolv SMCC ${ }^{\mathrm{TM}}$ (Penwest Pharmaceuticals) is a patented combination of MCC and colloidal silicon dioxide (CSD), known to work together synergistically to optimize product performance. Formulating with ProSolv $\mathrm{SMCC}^{\mathrm{TM}}$ has been shown to reduce binder usage by more than half, cutting tablet size consequently. Hence, it is ideally suited to highdose direct-compression formulations in which it has advantages in both flow and compactibility over conventional MCC.

\section{Dealing with difficult actives}

Many new drug candidates exhibit poor solubility and stability. Excipient compatibility is another issue with some of these compounds. Furthermore, some macromolecular peptide and protein drugs need to be protected and delivered safely through the gastrointestinal tract to the site of most active absorption. 


\section{Formulating a Moisture-Sensitive Active}

Corn starch has long been used as disintegrate in oral solid dosage forms. Physical modifications of corn starch, through partial pregelatinization (Starch $1500^{\mathrm{TM}}$, Colorcon) have added functional benefits in terms of flowability and lubricity, while retaining its disintegrant capability and moisture stability.

Superdisintegrants function primarily by drawing large amounts of water into the tablet while simultaneously swelling. It is this great affinity for water that can impact the stability of moisture-sensitive materials under accelerated storage conditions. Partially pregelatinized starchhas been shown to exhibit a lower propensity for moisture, thus providing excellent stabilization of formulations.

\section{Formulating a Poorly Soluble Active}

Almost $10 \%$ of currently marketed drugs are poorly soluble. Almost $40 \%$ of new chemical entities (NCE) are dropped due to solubility issues. Poor water solubility leads to poor dissolution kinetics and suboptimal bioavailability. NanoCrystal ${ }^{\circledR}$ (Elan Pharmaceuticals) and NanoEdge ${ }^{\circledR}$ (Baxter Healthcare) technologies involve decreasing the particle size of actives to nanometer size range, thus leading to an increase in the surface area and a subsequent increase in dissolution rate. These drug particles are stabilized against agglomeration by surface adsorption of selected proprietary GRAS excipients, such as ionic surfactants and block copolymers. The result is a colloidal dispersion, which can later be freeze dried or spray dried to yield nanoparticles in the 500-nm range. This is an attractive option for actives with high toxicity and low potency.

\section{Formulating a Poorly Absorbed Active}

Another major hurdle to effective oral drug delivery in humans is poor absorption of drugs through the epithelial membrane. Biopharmaceutical studies have shown that vitamin E TPGS ${ }^{\mathrm{TM}}$ (a-tocopheryl PEG 1000 succinate, Eastman Chemical Company) can be used as a safe and effective absorption enhancer for poorly absorbed drugs, such as cyclosporine and protease inhibitors. It functions so by enhancing the solubility and permeability of drugs.

\section{Working Around Drug-Excipient Incompatibility}

Excipients can interact with drugs in the solid state by: acting as a moisture source, providing surface contact points, lowering the drug melting point by forming a eutectic mixture, and acting as a reaction catalyst or chemical reactant. DI-TAB ${ }^{\mathrm{TM}}$ (dicalcium phosphate, Rhodia) is a directly compressible filler-binder that contains "mobile" water of crystallization. These water molecules can be transferred to other components in the formulation during tableting or aging. Rhodia has taken this established product and developed a product called A$\mathrm{TAB}^{\mathrm{TM}}$, anhydrousdicalcium phosphate. A-TAB ${ }^{\mathrm{TM}}$ is very stable at high temperatures and humidities, thus stabilizing the formulation.

One of the more common drug-excipient incompatibilities is the reaction between aldehydic sugars, such as lactose and primary and secondary amines, leading to the formation of Schiff's bases. These complex series of reactions lead to browning and discoloration of the dosage form. Despite being a carrier of choice for dry powder aerosol formulations, lactose may need to be replaced with a different carrier, such as mannitol or sucrose, when formulating primary and secondary amines (eg, tobramycin).

\section{Formulating Peptides/Proteins}

Progress in the development of peptides as useful drugs has been impeded in part by their rapid excretion, resulting in short circulating lifetimes. This generated considerable interest in improving the duration of action of drugs through conjugation with the water-soluble, biocompatible excipient, poly(ethylene glycol). Such conjugates have reduced enzymatic degradation rates and lengthened circulating lifetimes compared to the native compounds.

Other novel lipophilic carbohydrate excipients, termed oligosaccharide ester derivatives (OEDs), have been used to modify pharmacokinetic profiles of drugs. This technology is quite flexible, offering the ability to formulate drug molecules with modified-release characteristics and improved bioavailability. Another technology from the same company makes use of select carbohydrate excipients, such as trehalose and sucrose to stabilize molecules in the dry state, thereby preventing their physical and chemical degradation at ambient temperatures and above. These patent-protected drug delivery technologies are suited to the delivery of macromolecules, such as proteins and peptides by the pulmonary, oral, and injectable routes. 1 ,

\section{REGULATORY REQUIREMENT}

Regulatory requirements are part of the process of drug discovery and drug development. Regulatory requirements describe what is necessary for a new drug to be approved for marketing in any particular country. In the US, it is the function of the Food and Drug Administration (FDA) to establish these regulatory requirements. The European Medicines Agency (EMEA) and Japanese Pharmaceuticals and Medical Devices Agency (PMDA) are also important regulatory authorities in drug development. These three agencies oversee the three largest markets for drug sales.

Historically, the various regulatory authorities have had their own methods for obtaining regulatory approval, however the rising cost of meeting the demands of differing regulations led to the establishment of an International Conference on Harmonisation of Technical Requirements for Registration of Pharmaceuticals for Human Use $(\mathrm{ICH})$ in an attempt to co-ordinate and synthesize international regulatory requirements. The first Conference was held in Brussels in 1991, followed by ICH 2 in Orlando, Florida in 1993, and ICH 3 in Yokohama, Japan in 1995. The Fourth International Conference on Harmonisation, in July 1997, was once again in Brussels.

These systems of new drug approvals are extremely rigorous and costly. On average, it will cost a pharmaceutical company $\$ 359$ million to get one new medicine from the laboratory to the pharmacist's shelf, according to a February 1993 report by the Congressional Office of Technology Assessment. It takes 12 years on average for an experimental drugto travel from the laboratory to the medicine chest. Only five in 5,000 
compounds that enter preclinical testing will actually progress into human clinical trials, and of these five, only one is likely to be approved by the regulatory authorities. ${ }^{3,}$

2

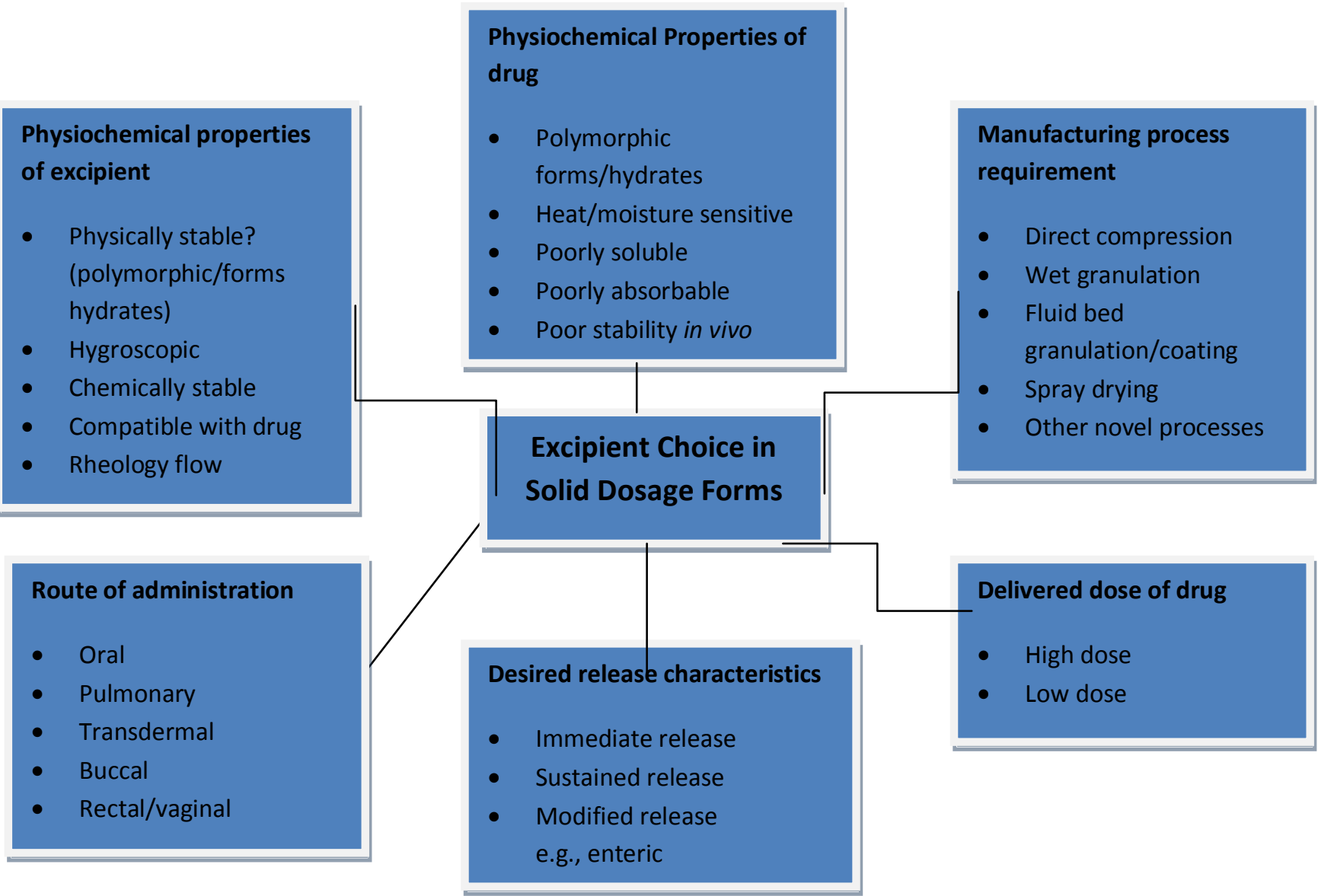

Figure 2: Factors to consider when choosing a novel excipient for solid dosage forms ${ }^{1}$

\section{NOVEL EXCIPIENTS AS DIFFERENT POLYMERS}

\section{Poly (amidoamide)dendrimers}

Such polymers containing one or more types of membrane-targeting antimicrobial agents immobilized on a substrate with activity in relevant biological environments, and methods of making and using thereof, are described herein. The antimicrobial agents retain their activity in the presence of blood proteins and/or in vivo due to improved molecular structures which allow for cooperative action of immobilized agents and hydrophilic chemistries which resist non-specific protein adsorption. Suitable molecular structures include branched structures, such as dendrimers and randomly branched polymers. The molecule structures may also include hydrophilic tethers which provide both flexibility and resistance to non-specific protein adsorption. The membrane targeting antimicrobial agent coatings can be applied to a variety of different types of substrates including medical implants such as vascular grafts, orthopedic devices, dialysis access grafts, and catheters; surgical tools, surgical garments; and bandages. The substrates can be composed of metallic materials, ceramics, polymers, fibers, inert materials such as silicon, and combinations thereof. The compositions described herein are substantially nonleaching, resistant to non-specific protein adsorption, and non-hemolytic. ${ }^{5,6,7}$

\section{Poly (L-lactide)-poly (oxyethylene)-poly (L-lactide)}

(c) 2011, JDDT. All Rights Reserved
Such block copolymers obtained in bulk, by a ring opening mechanism, from poly (ethylene glycol)s (PEG)s and L-lactide (LA), at $120-140^{\circ} \mathrm{C}$, in the absence of added catalysts are described. By using PEGs with different molecular masses, 3000 and 35000, respectively, and varying the initial molar ratio LA to PEG, two series of copolymers with different molecular masses, relative length of blocks and hydrophilicity were obtained.

The morphological characteristics of the copolymers were investigated by means of X-ray diffractometry, optical and scanning electron microscopy. The biological properties of the materials were determined by evaluating their cytotoxicity, cytocompatibility, hemocompatibility and degradability using different standard tests. The results obtained indicate that the block copolymers synthesized may be useful for biomedical applications, in particular as restorable drug vehicles. The materials are brittle and their mechanical properties are not appropriate for implant devices. ${ }^{\mathbf{8}, \mathbf{9}}$

\section{Poly(fumaric-co-sea-basic)}

Sea-basic acids are better candidates for bioadhesive delivery systems since, as hydrolysis proceeds, causing surface erosion, more and more carboxylic groups are exposed to the external surface. However, polylactides erode more slowly by bulk erosion.

In designing bioadhesive polymeric systems based on polylactides, polymers that have high concentrations of carboxylic acid are preferred. This can be accomplished 
by using low molecular weight polymers (Mw 2000), since low molecular weight polymers contain high concentration of carboxylic acids at the end groups. Measurement of Bioadhesive Properties using a tensile technique.

Hydrogel microspheres were prepared by dripping a polymer solution from a reservoir though microdroplet forming device into a stirred ionic bath. The specific conditions for alginate, chitosan, alginate/polyethylenimide (PEI) and carboxymethyl cellulose (CMC)

Polyacrylamide microspheres were produced by polymerizing an aqueous emulsion of acrylamide and bismethacrylamide in hexane.. This working solution was extensively degassed under water vacuum to remove dissolved oxygen which might inhibit the polymerization reaction.

It requires Gene transfer in humans as carriers for the plasmid DNA which can efficiently and safely carry the gene into the nucleus of the desired cells. A series of chemically different cationic polymers are currently being investigated for these purposes. Although many cationic polymers indeed condense DNA spontaneously, which is a requirement for gene transfer in most types of cells, the physicochemical and biopharmaceutical behavior of the current generation of polyp lexes severely limits an efficient gene transfer in vitro and especially in vivo.

This summarizes recent physicochemical and biological information on polyp lexes and aims to provide new insights with respect to this type of gene delivery system. Firstly, the chemical structure of frequently studied cationic polymers is represented. Secondly, the parameters influencing condensation of DNA by cationic polymers are described. Thirdly, the surface properties, solubility, aggregation behavior, degradation and dissociation of polyplexes are considered. The review ends by describing the in vitro and in vivogenetransfection behavior of polyplexes. ${ }^{\mathbf{1 0 , 1 1}, 12}$

\section{The Steryl (polylysine)}

It requires Gene transfer in humans as carriers for the plasmid DNA which can efficiently and safely carry the gene into the nucleus of the desired cells. A series of chemically different cationic polymers are currently being investigated for these purposes. Although many cationic polymersindeed condense DNAspontaneously, which is a requirement for gene transfer in most types of cells, the physicochemical and biopharmaceutical behavior of the current generation of polyp lexes severely limits an efficient gene transfer in vitro and especially in vivo.

This summarizes recent physicochemical and biological information on polyp lexes and aims to provide new insights with respect to this type of gene delivery system. Firstly, the chemical structure of frequently studied cationic polymers is represented. Secondly, the parameters influencing condensation of DNA by cationic polymers are described. Thirdly, the surface properties, solubility, aggregation behavior, degradation and dissociation ofpolyplexes are considered. The review ends by describing the in vitro and in vivogenetransfection behavior of polyp lexes.

It relates to the delivery of desired compounds (e.g., nucleic acids) into cells using releasable delivery systems which include complexing nucleic acids and delivery ligands and used in the following applications as in Gene Therapy and Nucleic Acid, Polymers for Drug and Nucleic Acid Delivery, Condensation template polymerization of DNA, Endosome Diruption and Gene Expression. ${ }^{13,14}$

Polyaspartic acid (PASP), (A metal corrosion inhibitor), biodegradable and environment friendly, is a kind of green chemicals of demand increasing globally. The synthesis and application of PASP is popular in many countries because the problem of environment has been paid more and more attention. The field of PASP application is not same with different molecular weight range.

\section{Properties:}

PASP can be used as scale and corrosion inhibitor in industrial circulating cool water system, boiler water, reverse osmosis, oilfield water and desalination plant. The effects will be even better than ordinary organophosphines. When used in situation of high hardness, high alkaline, high $\mathrm{pH}$ value and high concentration index. When built with PBTCA, the synergism is obvious.

As a metal corrosion inhibitor, PASP has good corrosion inhibition ability with $\mathrm{pH}>10$ and it also has good corrosion inhibition ability with low concentration for sea water. When built with organ phosphor, sodium tungstate, quatenary ammonium salt, zinc salt, molybdate, oxidized starch, and so on, the synergism is obvious.

As a nutrient absorption enhancer, PASP can be used in agriculture. When PASP is applied to fertilizer, it can enhance the availability of $\mathrm{N}, \mathrm{P}$, and $\mathrm{K}$ resulting in increased yields because of its high capacity for chelating metal ions.

As a new polymer, PASP can be reacted with cross linker into superabsorbent agent. This product with properties of non-pollution and fully biodegradation can be used for hygiene products. ${ }^{15,16}$ 
SUMMARY TABLE-1

\begin{tabular}{|c|c|c|c|}
\hline $\begin{array}{l}\text { SR } \\
\text { NO. }\end{array}$ & COMPOUND NAME & POLYAMIDO POLYETHER & $\begin{array}{l}\text { POLYETHYLENE } \\
\text { POLYHISTIDYL GLYCOL }\end{array}$ \\
\hline 1. & Non-Proprietary Name: & Amido polyether & Glycolic acid \\
\hline 2. & Formula: & $\mathrm{C}_{3} \mathrm{H}_{9} \mathrm{SiO}\left[\mathrm{C}_{2} \mathrm{H}_{6} \mathrm{SiO}\right]_{400}\left[\mathrm{C}_{29} \mathrm{H}_{59} \mathrm{O}_{3} \mathrm{~N}_{2}\right]_{8} \mathrm{SiC}_{3} \mathrm{H}_{9}$ & $\mathrm{C}_{2} \mathrm{H}_{4} \mathrm{O}_{3}$ \\
\hline 3. & CAS No.: & None & $79-74-1$ \\
\hline 4. & Mol Weight: & $34400 \mathrm{~g} / \mathrm{mole}$ & $76.05 \mathrm{~g} / \mathrm{mol}$ \\
\hline 5. & Chemical Name: & $\begin{array}{l}\text { Siloxanes and silicones, Dimethyl, methyl 3- } \\
\text { [(2-lauroxy polyethyleneglycol Acetamido } \\
\text { ethyl) amino] propyl, trimethylendblocked }\end{array}$ & 2-hdroxyethanoic acid \\
\hline 6. & Synonyms: & $\begin{array}{l}\text { Amido polyether modified silicone fluid, APM } \\
\text { fluid, BY16-878 }\end{array}$ & Hydroxyacetic acid \\
\hline 7. & Description: & Amine odor, with pale yellow, colored liquid & $\begin{array}{l}70 \% \text { soluble in water } \\
\text { Crystalline white powder } \\
\text { OdorlessHygroscopic }\end{array}$ \\
\hline 8. & Structure: & 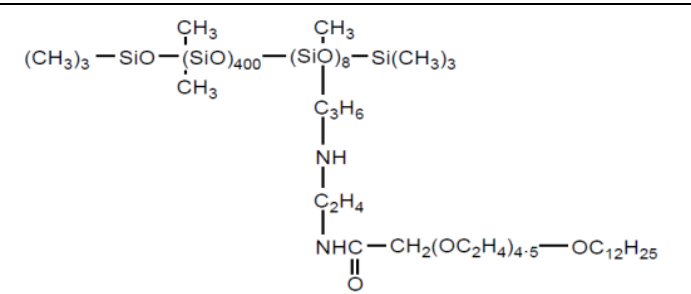 & IO \\
\hline 9. & Related Compounds: & $\begin{array}{lcl}\text { Organic } & \text { amines } & \text { and } \\
\mathrm{HOOCCH}_{2}\left(\mathrm{C}_{2} \mathrm{H}_{40}\right)_{4} .5 \mathrm{C}_{12} \mathrm{H}_{25} & \\
\end{array}$ & Lactic acid, glycerol, acetic acid \\
\hline 10. & $\begin{array}{l}\text { Pharmaceutical } \\
\text { Application: }\end{array}$ & Surface active agents & $\begin{array}{l}\text { keratolytic } \\
\text { Acne treating agent }\end{array}$ \\
\hline 11. & Function Category: & Fabric softner & Used in skin treatments \\
\hline 12. & Storage: & Store in cool and dry container & Store at cool temperature \\
\hline 13. & Stability: & React with strong acids & It is quite stable \\
\hline 14. & Safety: & Not explosive & Strong irritant \\
\hline 15. & Handling Precaution: & Skin irritant & $\begin{array}{l}\text { Avoid breathing dust } \\
\text { Avoid eyes contact }\end{array}$ \\
\hline
\end{tabular}

SUMMARY TABLE -2

\begin{tabular}{|c|c|c|c|}
\hline $\mathbf{S ~ N}$ & COMPOUND NAME & STERYL POLY-LACTIDE & STERYL POLY LYSINE \\
\hline 1. & Non-Proprietry Name: & Polyester & L-lysine monohydrochloride \\
\hline 2. & Formula: & $\left(\mathrm{C}_{4} \mathrm{H}_{4} \mathrm{O}_{4}\right) \mathrm{Y}$ & $\mathrm{C}_{6} \mathrm{H}_{15} \mathrm{BrN}_{2} \mathrm{O}_{2} \mathrm{C}_{6} \mathrm{H}_{15} \mathrm{BrN}_{2} \mathrm{O}_{2}$ \\
\hline 3. & CAS No.: & $33135-50-4$ & $657-27-2$ \\
\hline 4. & Mol Weight: & Measured by the DSC & $182.62 \mathrm{~g} / \mathrm{mole}$ \\
\hline 5. & Chemical Name: & 4-dioxane-2,5-dione & L-Lysine Monohydrochloride \\
\hline 6. & Synonyms: & $\begin{array}{l}\text { Polylactide, } \text { polylactic acid, PLA; } \\
\text { Polyglycolide, Polyglycolic acid, PGA; }\end{array}$ & $\begin{array}{l}\text { 2,6-Diaminohexanoic acid } \\
\text { hydrochloride;L-Lysine Hydrochloride; } \\
\text { Lyamine;Lysine Hydrochloride. }\end{array}$ \\
\hline 7. & Description: & $\begin{array}{l}\text { React slowly with water } \\
\text { Forms in solid pallets or powder }\end{array}$ & $\begin{array}{l}\text { Off white colored, granular or powdered } \\
\text { solid }\end{array}$ \\
\hline 8. & Structure: & & \\
\hline 9. & Related Compounds: & Polylactide, polyglycoside & L-Lysine, N2-L-histidyl \\
\hline 10. & $\begin{array}{l}\text { Pharmaceutical } \\
\text { Application: }\end{array}$ & Used mainly in vaccine preparations. & $\begin{array}{l}\text { Bio reagent suitable for cell cultures. } \\
\text { Charge enhancer for coating cell surface. }\end{array}$ \\
\hline 11. & Function Category: & A polymer & A polymer \\
\hline 12. & Storage: & Store at cool temperature & Store at cool temperature \\
\hline 13. & Stability: & Less stable & \\
\hline 14. & Safety: & Material burnt if exposed to heat source & Hazardous to skin and eye contact \\
\hline 15. & Handling Precaution: & $\begin{array}{l}\text { Avoid eye contact } \\
\text { Avoid breathing dust }\end{array}$ & May be toxic at high temperature \\
\hline
\end{tabular}




\section{CONCLUSION:}

In short it can be said that challenges in formulation and drug delivery of active ingredients are impossible to solve with old excipients. Therefore, more research will be focused on development of novel excipients for efficient drug delivery at targeted site. Individual approval of excipient by separate registration process from finished product registration will provide guide to pharma companies for effective use of novel excipient in safe

\section{REFERENCES}

1. Flickinger B. "Functional excipients: getting creative with the chemistry" PharmaceutForm, 2009, Vol: 1, Issue:1

2. Cunningham CR. Kinsey BR, Scattergood LK, "Evaluation of a partially pregelatinize starch in comparison with superdisintegrants in a direct-compression hydro-chlorothiazide formulation". American Association of Pharmaceutical Scientists, Annual volume.

3. Karmarkar A.B. (2012) Novel excipients: The way ahead for drug development" Pharmabiz, 2008, Vol. 11

4. Christopher D, Goldring J, Velagaleti R, Brock W, and Osterberg W, "Regulatory Update: The IPEC Novel Excipient Safety Evaluation Procedure"Pharmaceutical Technology, 2009, Vol: 33, Issue: 11 .

5. Gabriella N, Laszlo H, Istvan J, Ildiko P, JúliaVand Julianna K, "Polyamidoaminedendrimer impairs mitochondrial oxidation in brain tissue" Journal Of Biotechnology, 2013, Vol:1, Issue:9

6. Shao N, Su Y, Hu J, Zhang J, Zhang H, Cheng Y, "Comparison of generation 3 polyamidoaminedendrimer and generation 4 polypropyleniminedendrimer on drug loading, complex structure, release behavior, and cytotoxicity" Dovepress: an acess to scientific and medical research, 2011, Vol:6

7. Mathias Ulbricht "Advanced functional polymer membranes" Elsevier: Science direct, polymer, vol: 47, 2217-2262.

8. Hirenkumar K. Makadia and Steven J. Siegel "Poly Lactic-coGlycolic Acid (PLGA) as Biodegradable Controlled Drug Delivery Carrier" Polymers, 2011, Vol: 3, 1377-1397. dosage. Due to this, research on novel excipient will also foster leading to their use in different dosage forms and routes. All these activities will promote innovation in novel excipients by providing ease of market approach and penetration to excipient companies. Final outcome of this will be effective, safe and reliable medicine to patient leading to betterment of mankind.
9. Ivaylo V, Iliyana V and Victoria I, "synthesis of multifunctional poly(D, L-lactide)-poly (oxyethylene)-poly(D,L-lactide) triblock copolymers" Polymer Journal, 2013, Vol:45

10. Stevanovi M, Uskokovi D, "Poly(lactide-co-glycolide)-based Micro and Nanoparticles for the Controlled Drug Delivery of Vitamins" Current Nanoscience,2009, Vol: 5, Issue 1.

11. Brandon V. S., Shahana S. K., Omar Z. F., Khademhosseini A, and Nicholas A. P., "Hydrogels in Regenerative Medicine" Adv. Mater,2009, Vol: 21, 3307-3329.

12. Bouissou, C.; Rouse, J.J.; Price, R.; van der Walle, C.F. The influence of surfactant on PLGA microsphere glass transition and water sorption: Remodeling the surface morphology to attenuate the burst release. Pharm. Res. 2006, Vol:23, 1295-1305.

13. Sung W.K. "In Vitro Transfection with Oligonucleotide DNA Using Polylysine Copolymers" Cold Spring HarbProtoc, 2012. Vol:1

14. Jonathan M. B., Choi J.G, Mahato R.I, Park J.S and Kim S.W, "pH-Sensitive Cationic Polymer Gene Delivery Vehicle: $N$-Acpoly(L-histidine)-graft-poly(L-lysine) Comb Shaped Polymer"Bioconjugate Chem., 2000, Vol: 11, 637-645.

15. Wang H. P., Wu Q., Li, N. Gu C. M. "Copper corrosion inhibition by polyaspartic acid and imidazole" Materials and Corrosion, 2012, Vol:64, Issue:4

16. Seung I. K, Seok K. M, and Kim J.H. "Synthesis and Characterization of Novel Amino Acid-conjugated Poly(aspartic acid) Derivatives" Bull. Korean Chem. Soc., 2008, Vol. 29, No. 10 